Tempo Social; Rev. Sociol. USP, S. Paulo, 7(1-2): 83-103, outubro de 1995.

\title{
Sobre a analítica do poder de Foucault
}

\author{
ANTÔNIO C. MAIA \\ "L'ouvre de Foucault se ré-encheine avec les \\ grandes ouvres qui ont changé por nous ces \\ que signifie penser" \\ (Deleuze, 1986, p. 128)
}

RESUMO: Compreender a forma pela qual se estruturam as relações sociais, em especial as relações desiguais de obediência e dominação que justificam a autoridade e a natureza das obrigações políticas, tem sido uma tarefa constante do pensamento humano. Neste texto sustentamos que Michel Foucault deu uma contribuição inegável a uma compreensão melhor desta ordem de fenômenos. Na primeira parte examinamos algumas das características do seu conceito de poder. Na segunda, privilegiamos um outro eixo de análise, acompanhando as transformações que este conceito sofreu ao longo dos anos 70 em sua obra.

\section{Introdução}

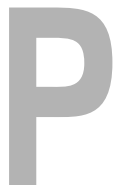

oucos autores do cenário contemporâneo trilharam tantas áreas do saber como Foucault: da epistemologia das ciências humanas à ética, da literatura à sexualidade, da loucura à punição. Mas, o estudo do poder foi o causador da maior repercussão. As suas investigações, ao longo dos anos 70, em torno da problemática do poder, com suas características, táticas e estratégias o projetaram como o filósofo francês - ao lado de Jacques Derrida - de maior presença no cenário cultural alemão e anglo-saxão. Entretanto, esta parte de seu trabalho não foi objeto de uma or-

UNITERIMOS:

Foucault, conceito de poder, bio-poder, governamentalidade.

Professor da Faculdade de Direito da UERJ e do Departamento de Direito e do curso de especialização em Filosofia da PUC-RJ 
MAIA, Antônio C. Sobre a analítica do poder de Foucault. Tempo Social; Rev. Sociol. USP, S. Paulo, 7(1-2): 83-103, outubro de 1995.

Agradeço a Márcia Bernardes a ajuda que me deu na preparação do texto para a publicação

A única exposição sistematizada de Foucault a respeito das suas reflexões sobre poder se encontra no texto Sujeito e poder (1982). ganização de suas premissas, nem de uma sistematização de seus resultados. Algumas causas podem ser apontadas para justificar esta situação.

Em primeiro lugar, a própria características das investigações de Foucault, cujas pesquisas avançaram impulsionadas por uma infatigável vontade de saber, onde a curiosidade o levava constantemente a novos assuntos e diferentes domínios, deixando, em geral, de lado as reflexões de caráter mais tipicamente metodológico. Um estilo de trabalho que demarcava certos domínios - por exemplo, medicina, práticas punitivas, emergência das ciências humanas nos séculos XVIII e XIX_-, submetendo-os a um minudente exame, à luz de uma erudição excepcional, privilegiando sempre os dados empíricos obtidos em suas pesquisas de natureza histórico-filosóficas. Este privilégio do material positivo pesquisado, as conclusões parciais à medida dos desdobramentos dos estudos, os instrumentos conceituais forjados a partir da análise do material examinado, davam o tom de um trabalho mais preocupado em sacudir as evidências e perturbar as nossas familiaridades do que em estruturar uma obra sistematicamente integrada. Aliado a isto, uma desconfiança em relação às generalizações e grandes sínteses contribuíram para uma situação na qual certos assuntos se encontram expostos de forma não muito articulada. Em relação à problemática do poder, estas características até aqui destacadas do projeto de Foucault ensejaram uma reflexão — que embora original e profunda - não foi merecedora de nenhum grande trabalho de exposição e sistematização ${ }^{1}$. O que se observa são inúmeras e esparsas referências, espalhadas pelos mais diversos textos: livros, cursos, conferências e entrevistas.

Este breve trabalho procura alinhavar considerações a respeito da análise foucaultiana do poder. Tal problemática será enfocada a partir de dois eixos. Primeiramente, destacar-se-á certos traços de seu trabalho acerca desta questão; em segundo lugar, serão acompanhadas algumas modificações e diferenciações expostas e explicitadas ao longo de suas investigações: poder disciplinar, o bio-poder e a governamentalidade.

Antes ainda de iniciar a descrição de certos traços do conceito de poder, cabe destacar que Foucault não tem uma teoria geral do poder, a - histórica, podendo ser aplicada a todas as relações de poder existentes em sociedade, em qualquer contexto. Ao contrário, ele não pretende fundar uma teoria geral e globalizante, e sim trabalhar uma analítica de poder capaz de dar conta do seu funcionamento local, em campos e discursos específicos e em épocas determinadas. Como ele destaca: "O que está em jogo nas investigações que virão a seguir é dirigirmos menos para uma 'teoria' do poder que para uma 'analítica' do poder: para uma definição do domínio específico formado pelas relações de poder e determinação dos instrumentos que permitam analisá-lo" (Foucault, 1979b, p. 80). O ponto de vista adotado pela analítica do poder assume uma reflexão com âmbito mais limitado a respeito desta problemática, evitando determinadas questões - como, por exemplo, a respeito da origem do poder - e adotando uma perspectiva eminentemente descritiva, procurando identificar e explicitar os diferentes mecanismos, táticas e estratégias 
MAIA, Antônio C. Sobre a analítica do poder de Foucault. Tempo Social; Rev. Sociol. USP, S. Paulo, 7(1-2): 83-103, outubro de 1995.

empregadas, bem como a forma de funcionamento, das relações de poder em sociedade. Como salienta o autor de Vigiar e punir:

“(...) o problema não é de constituir uma teoria do poder que teria como função refazer o que um Boulainvilliers ou Rousseau queriam fazer. Todos os dois partem de um estágio originário em que todos os homens são iguais, e depois o que acontece? Invasão histórica para um, acontecimento mítico para outro, mas sempre aparece a idéia de que, a partir de um momento, as pessoas não tiveram mais direitos e surgiu o poder. Se o objetivo for construir uma teoria do poder, haverá sempre a necessidade de considerá-lo como algo que surgiu em um determinado momento, de que se deveria fazer a gênese $e$ depois a dedução. Mas se o poder na realidade é um feixe aberto, mais ou menos coordenado (e sem dúvida mal coordenado) de relações, então o único problema é munir-se de princípios de análise que permitam uma analítica do poder" (grifo meu) (Foucault, 1979a, p. 154).

É importante observar com clareza as ambições de Foucault no tocante às análises formuladas pela genealogia do poder. Em geral as dimensões e objetivos de sua empreitada não são corretamente apreciados por seus leitores. Críticas aos resultados das investigações realizadas por Foucault a respeito da problemática do poder, por vezes não estão atentas aos limites - por ele reconhecidos de suas pesquisas. Quem destaca com precisão a forma de trabalho e o âmbito da reflexão de Foucault acerca do poder é Roberto Machado:

"Mas é preciso ser menos geral e englobante. Porque a análise de Foucault sobre a questão do poder é o resultado de investigações delimitadas, circunscritas, com objetivos bem demarcados. Por isso, embora as vezes suas afirmações tenham uma ambição englobante, inclusive pelo tom muitas vezes provocativo e polêmico que as caracteriza, é importante não perder de vista que se trata de análises particularizadas, que não podem e não devem ser aplicadas indistintamente sobre novos objetos, fazendo-lhe assim, assumir uma postura metodológica que lhes daria universalidade” (Machado, 1979, p. XII).

A partir destas considerações e delimitado o escopo do projeto foucaultiano a respeito do poder, o primeiro traço que interessa destacar nesta analítica é o abandono de uma visão tradicional do poder onde sua atuação se basearia fundamentalmente em seu aspectos negativos: proibindo, censuran- 
do, interditando, reprimindo, coagindo, etc. Como ele afirma: "Já repeti cem vezes que a história dos últimos séculos da sociedade ocidental não mostrava a atuação de um poder essencialmente repressivo" (Foucault, 1979b, p. 79). Talvez esteja aí um dos aspectos mais ricos de sua análise. É difícil avaliar se foi ele que inaugurou esta visão da problemática do poder, porém com certeza poucos enfatizaram tão tenazmente está idéia. Ora, chega a causar estranheza e se imaginarmos que as relações de poder se fundam exclusivamente em um caráter negativo: como explicar o sucesso das inúmeras redes de dominação existentes em sociedade? Como explicar a relativa tranqüilidade do poder burguês em uma sociedade injusta e desigual, onde uma iníqua divisão de bens e poder vem se perpetuando com certa facilidade? Talvez seja modificando nossa percepção do fenômeno do poder que possamos entender melhor esta dinâmica. Assim, parece fazer mais sentido sustentar a seguinte posição: "o que faz com que o poder se mantenha e que seja aceitoé simplesmente que ele não pesa só como a força que diz não, mas que de fato ele permeia, produz coisas, induz ao prazer, forma saber, produz discurso" (Foucault, 1979a, p. 8).

Por conseguinte, ao enfatizar o aspecto produtor do poder, Foucault se insurge contra uma visão do poder que o encara predominantemente como uma expressão de uma operação que teria a forma de enunciação da lei e do discurso da proibição, com toda uma série de efeitos negativos: exclusão, rejeição, ocultação, obstrução, etc. Com efeito, a partir desta perspectiva é a lei da interdição e da censura que atravessa todo o corpo social - do Estado à família, do príncipe ao pai; dos tribunais à toda a parafernália da punições quotidianas - como forma por excelência de exercício do poder. Para ele impõe-se uma mudança neste enfoque, encarando o exercício do poder menos em termos jurídicos e de proibição e mais como técnicas e estratégias com efeitos produtivos. Como ele afirma, "Temos que deixar de descrever sempre os efeitos do poder em termos negativos: ele 'exclui', 'reprime', 'recalca', 'censura', 'abstrai', 'mascara', 'esconde'. Na verdade o poder produz realidade, produz campos de objetos e rituais da verdade. O indivíduo e o conhecimento que dele se pode ter se originam nessa produção" (Foucault, 1977, p. 172).

Dentro desta perspectiva, Foucault propõe uma analítica do poder onde é abandonado o modelo legal: "É preciso construir uma analítica do poder que não tome o Direito como modelo" (Foucault, 1979b, p. 87). Desta forma, procura-se fugir de uma tradição onde se utiliza o modelo formal e centralizador do Direito como parâmetro à compreensão das relações de poder, modelo este que tem se revelado insuficiente para dar conta da incessante, fluida e matizada movimentação das relações políticas e de poder. Ademais, esta concepção jurídica do poder ainda guarda influência — bem maior que a correntemente admitida — da representação de poder estruturada quando da consolidação dos Estados Nacionais na Europa, sob o regime monárquico. Como salienta Foucault: "No fundo, apesar das diferenças de época e de objetivos, a representação do poder permaneceu marcada pela monarquia. No pensamento e na análise política ainda não cortaram a cabeça do rei" (Foucault, 
MAIA, Antônio C. Sobre a analítica do poder de Foucault. Tempo Social; Rev. Sociol. USP, S. Paulo, 7(1-2): 83-103, outubro de 1995.

1979b, p. 86).

Ao afastar-se do modelo legal - afinal o poder não é algo de que se tenha propriedade, que se "troque" ou "venda" - Foucault aponta para uma nova percepção deste fenômeno. Assim, o poder não deve ser conhecido como algo detido por uma classe (os dominantes) que o teria conquistado, alijando definitivamente a participação e a atuação dos dominados ${ }^{2}$; ao contrário, as relações de poder presumem um enfrentamento perpétuo. Desta maneira, o funcionamento do poder é melhor compreendido através da idéia de que se exerce por meio de estratégias e que seus efeitos não são imputáveis a uma apropriação mas a manobras táticas e técnicas. Como ele explica uma das mais esclarecedoras passagens de Vigiar e Punir sobre a dinâmica do poder: "Ora, o estudo desta microfísica supõe que o poder nela exercido não seja concebido como uma propriedade, mas como uma estratégia, que seus efeitos de dominação não sejam atribuídos a uma 'apropriação', mas a disposições, a manobras, a táticas, a técnicas, a funcionamentos; que se desvende nele antes uma rede de relações sempre tensas, sempre em atividade, que um privilégio que se pudesse deter; que lhe seja dado como modelo antes a batalha perpétua que o contrato que faz uma cessão ou uma conquista que se apodera de um domínio. Temos, em suma, que admitir que esse poder se exerce mais do que se possui, que não é 'privilégio' adquirido ou conservado da classe dominante, mas o efeito conjunto de suas posições estratégicas - efeito manifestado e às vezes reconduzido pela posição dos que são dominados" (Foucault, 1977, p. 29).

A perspectiva aberta pela analítica do poder vai impor, também, um deslocamento sensível, em relação às análises tradicionais sobre esta noção, no que concerne ao papel do Estado. Ora, para Foucault, "uma sociedade sem relações de poder somente pode ser uma abstração" (Foucault, 1982, p. 222), isto implica que qualquer agrupamento humano vai estar sempre permeado por relações de poder, posto que a existência deste tipo de relaçãoé coexistente à vida social. Desta perspectiva, o Estado parece perder um certo privilégio que a análise política lhe tem garantido. Isto se dá na medida em que a instituição estatal, via de regra percebida como o foco originador das relações de poder, na analítica do poder vai ter seu papel redimensionado. $\mathrm{O}$ Estado não detém a prerrogativa de ser o centro constituidor das relações de poder. O fenômeno da dominação, com as inúmeras relações de poder que pressupõe, preexiste ao Estado. O que se observa é que a partir da consolidação do Estado Nacional, como forma por excelência de organização política, paulatinamente com o alargamento das funções, há uma captura de focos de poder pelo aparelho do Estado. Como assevera: "É certo que nas sociedades contemporâ-
${ }^{2}$ Refutando a perspectiva que veria numa oposição dominantes $\mathrm{X}$ dominados, o eixo central da articulação das relações de poder Foucault propõe o seguinte: "que o poder vem de baixo; isto é, não há, no princípio das relações de poder, e como matriz geral, uma oposição binária e global entre os dominadores e os dominados, dualidade que repercute de alto a baixo e sobre grupos cada vez mais restritos até as profundezas do corpo social. Devese, ao contrário, supor que as correlações de forças múltiplas que se formam e atuam nos aparelhos de produção, nas famílias, nos grupos restritos e instituições, servem de suporte a amplos efeitos de clivagem que atravessam o conjunto do corpo social. Estes formam, então, uma linha de força geral que atravessa os afrontamentos locais e os liga entre si; evidentemente, em troca, procedem as redistribuições, alinhamentos, homogeneizações, arranjos de série, convergências, desses afrontamentos locais. As grandes dominações são efeitos hegemônicos continuamente sustentados pela intensidade destes afrontamentos" (Foucault, 1979b, p. 90). 
neas o Estado não é simplesmente uma das formas especificas de exercício do poder - mesmo se for a mais importante - mas, de um certo modo, todas as formas de relações de poder devem a ele se referir. Todavia isto não se dá porque elas se derivam do Estado; mas porque as relações de poder vem sendo paulatinamente colocadas sob o controle do Estado" (Foucault, 1982, p. 224).

A pesquisa de Foucault impõe um deslocamento em relação ao Estado ao identificar a existência de uma série de relações de poder na sociedade atual que se colocam fora do Estado e que não podem de maneira alguma ser analisadas em termos de soberania, de proibição ou de imposição de uma lei. Eis que: "entre cada ponto do corpo social, entre homem e mulher, entre membros de uma família, (...) entre cada um que sabe e cada um que não sabe, existem relações de poder" (Foucault, 1980a, p. 187). Tais relações, obviamente, não podem ser percebidas como projeções do poder do Estado. Dar conta destas relações é uma das preocupações desta analítica, pois sem entendêlas dificilmente se poderá alterar efetivamente o jogo do poder na sociedade. Mas não se negligencia o papel do Estado, apenas este papel é deslocado em relação às análises tradicionais. Como esclarece:

"Situar o problema em termos de Estado significa continuar situando-o em termos de soberano e soberania, o que quer dizer, em termos do Direito. Descrever todos esses fenômenos do poder como dependentes do aparato estatal significa compreendê-los como essencialmente repressivos: o exército como poder de morte, polícia e justiça como instâncias punitivas, etc. Eu não quero dizer que o Estado não é importante; o que quero dizer é que as relações de poder, e, conseqüentemente, sua análise se estendem além dos limites do Estado. Em dois sentidos: em primeiro lugar porque o Estado, com toda a onipotência do seu aparato, está longe de ser capaz de ocupar todo o campo de reais relações de poder, e principalmente porque o Estado apenas pode operar com base em outras relações de poder já existentes. $O$ Estado é a superestrutura em relação a toda uma série de redes de poder que investem o corpo, sexualidade, família, parentesco, conhecimento, tecnologia e etc." (grifo meu) (Foucault, 1980a, p. 122).

Um segundo aspecto, ainda em relação ao Estado, reside no fato do abandono de qualquer modelo centralizador. Ou seja, o poder não deve ser pensado como fundamentalmente emanado de um ponto (em geral, identificado com o Estado). Deve-se ter, pois, em mente, na procura de uma compreensão da dinâmica das relações de poder, a idéia de uma rede. Rede esta que permeia todo o corpo social, articulando e integrando os diferentes focos de poder (Estado, escola, prisão, hospital, asilo, família, fábrica, vila operária 
MAIA, Antônio C. Sobre a analítica do poder de Foucault. Tempo Social; Rev. Sociol. USP, S. Paulo, 7(1-2): 83-103, outubro de 1995.

etc.) que se apóiam uns nos outros.

Ao lado deste deslocamento da análise tradicional, é estabelecido também um dos princípios da analítica do poder: "o poder é um feixe de relações mais ou menos piramidalizado, mais ou menos coordenado" (Foucault, 1979a, p. 248). Com efeito, esta assertiva conduz a uma forma diferente de perceber o poder, pois através deste modelo relacional abre-se a possibilidade de compreender com mais acuidade a dinâmica, fragmentada, móvel e, às vezes contraditória, do poder em funcionamento na sociedade. Ora, dentro desta perspectiva o poder só pode ser concebido como algo que existe em relação, envolvendo forças que se chocam e se contrapõe. Deve-se frisar esta característica pois ela é absolutamente essencial à compreensão foucaultiana de poder. Afinal, "o poder é uma relação de forças ou antes, toda relação de força é uma "relação de poder"' (Deleuze, 1986, p. 77). A partir desta idéia temos um dos princípios da analítica do poder: deve se ter sempre em mente o reconhecimento de uma pluralidade de correlações de forças ${ }^{3}$ - constitutivas das relações de poder - que atravessam todo o corpo social. Assim, este aspecto relacional informa toda a perspectiva foucaultiana, como ele explica:

"O que caracteriza o poder que estamos analisando é que traz à ação relações entre indivíduos (ou entre grupos). Para não nos deixar enganar; só podemos falar de estruturas ou de mecanismo de poder na medida em que supomos que certas pessoas exercem poder sobre outras. O termo 'poder'designa relacionamentos entre parceiros (e com isto não menciono um jogo de soma zero, mas simplesmente, e por ora me referindo em termos mais gerais, a um conjunto de ações que induzem a outras ações, seguindo-se uma às outras)" (Foucault, 1982, p. 217).

É dentro dessa natureza relacional, inerente ao funcionamento do poder, que as relações se encontram menos envolvidas em confronto face - à face, que possivelmente paralisaria ambos os lados imersos em um antagonismo constante. Há nas relações de poder um enfrentamento constante e perpétuo. Como corolário desta idéia teremos que estas relações não se dão onde não haja liberdade. Na definição de Focault a existência de liberdade, garantindo a possibilidade de reação por parte daqueles sobre os quais o poder é exercido, apresenta-se como fundamental. Não há poder sem liberdade e sem potencial de revolta. As relações de poder não são relações de constrangimento físico absoluto (logo a escravidão ou relação com um homem acorrentado não caracteriza uma relação de poder). Como ele explicita:

"O poder é exercido somente sobre sujeitos livres e apenas enquanto são livres. Por isto, nós nos referimos a sujeitos individuais ou coletivos que são encarados sob um leque de possibilidades no qual inúmeros modos de agir, inúmeras reações e comporta-

\footnotetext{
Como destaca Foucault em uma das páginas mais esclare-cedoras sobre este assunto: "Parece-me que se deve compreender o poder, primeiro como uma multiplicidade de correlações de força imanentes ao domínio onde se exercem e constitutivas de sua organização; o jogo que, através de lutas e afrontamentos incessantes as transforma, reforça, inverte; os apoios que tais correlações de força encontram uma nas outras, formando cadeias ou sistemas ou, ao contrário, as defasagens e contradições que as isolam entre si; enfim, as estratégias em que se originam e cujo esboço geral ou cristalização institucional toma corpo nos aparelhos estatais, na formulação da lei, nas hegemonias sociais" (1979b, p. 88).
} 
MAIA, Antônio C. Sobre a analítica do poder de Foucault. Tempo Social; Rev. Sociol. USP, S. Paulo, 7(1-2): 83-103, outubro de 1995.

${ }^{4}$ Este aspecto do conceito de poder de Foucault se encontra explicitado em The subject and power (1982, p. 220), texto fundamental à compreensão desta noção. Como esclarece Foucault: "Quer isto dizer que se deve procurar o caráter próprio para as relações de poder na violência, que deve ter sido sua forma primitiva, seu segredo permanente e seu último recurso, que em sua análise final, aparece como sua natureza real quando ela é forçada a tirar sua máscara e mostrar-se como realmente é? De fato, o que define uma relação de poder é que ela é um modo de agir que não atua direta e imediatamente sobre os outros. Ao invés, ele atua sobre suas ações: uma ação sobre outra ação, sobre ações existentes ou sobre aquelas que podem surgir no presente e no futuro. Uma relação de violência age sobre um corpo ou sobre coisas; ela força, dobra, destrói ou fecha a porta a todas as possibilidades. O seu pólo oposto pode ser apenas a passividade e, ao se deparar com qualquer resistência, sua única opção é tentar minimizá-la. Por outro lado, uma relação de poder somente pode ser articulada com base em dois elementos que são indispensáveis tratando-se realmente de uma relação de poder: que o 'outro' (aquele sobre quem o poder vai ser exercido) seja plena- mentos observados podem ser obtidos. Onde os fatores determinantes saturam o todo não há relação de poder; escravidão não é uma relação de poder pois o homem está acorrentado (Neste caso fala-se de uma relação de constrangimento físico). Conseqüentemente, não há confrontação face a face entre poder e liberdade, que são mutuamente excludentes (a liberdade desapareceria sempre que o poder fosse exercido), mas uma interação muito mais complicada. Nessa relação, a liberdade pode aparecer como condição para exercício do poder (simultaneamente sua pré-condição, já que a liberdade precisa existir para $o$ 'poder'ser exercido e, também, seu apoio uma vez que sem a possibilidade de resistência, o poder seria equivalente à determinação física)" (Foucault, 1982, p. 221).

Um outro aspecto interessante reside no papel desempenhado pela violência nesta concepção de poder. Sem descartar a importância da utilização do recurso à violência por aqueles que exercem o poder — não esquecendo que o que se oferece à análise são as relações de poder — Foucault vai afirmar que a violência pode ser um instrumento utilizado nas relações de poder mas não um princípio básico da sua natureza ${ }^{4}$. A atuação do poder se dá de formas muito mais sutis, não se exercendo basicamente em aspectos negativos - o poder reprime, obstaculiza, etc., ou através da violência física. Diferentemente, o poder tem um aspecto produtivo fundamental. Deste modo, o exercício do poder deve ser compreendido como uma maneira pela qual certas ações podem estruturar o campo de outras possíveis ações. Como afirma:

"Em si mesmo o poder não é violência nem consentimento o que, implicitamente, é renovável. Ele é uma estrutura de ações; ele induz, incita, seduz, facilita ou dificulta; ao extremo, ele constrange ou, entretanto, é sempre um modo de agir ou ser capaz de ações. Um conjunto de ações sobre outras ações" (Foucault, 1982, p. 220).

Assim, as relações de poder se dão em um campo aberto de possibilidades onde, embora constate-se o fato de encontrar-se todo o tecido social imerso em uma ampla rede de relações de poder, não temos como corolário a existência de um poder onipresente, esquadrinhando todos os recantos da vida em sociedade levando a uma situação na qual não haveria espaço a resistências e alternativas de transformação. A capacidade de recalcitrar, de se insurgir, de se rebelar e resistir são elementos constitutivos da própria definição de poder. Desta forma, "digo simplesmente: a partir do momento em que há uma relação de poder, há uma possibilidade de resistência. Jamais somos aprisionados pelo poder: podemos sempre modificar sua dominação em condições 
MAIA, Antônio C. Sobre a analítica do poder de Foucault. Tempo Social; Rev. Sociol. USP, S. Paulo, 7(1-2): 83-103, outubro de 1995.

determinadas e segundo uma estratégia precisa" (Foucault, 1979a, p. 241). Novamente nos deparamos com um ponto fundamental da analítica do poder. Importa observar o seguinte: a possibilidade de resistência se apresenta em múltiplos focos (da mesma maneira que o poder funciona a partir de uma multiplicidade de pontos no tecido social). Como afirma:

“que lá onde há poder há resistência e, no entanto (ou melhor, por isso mesmo) esta nunca se encontra em posição de exterioridade (...) Não existe, com respeito ao poder, um lugar da grande recusa - alma da revolta, foco de todas as rebeliões, lei pura do revolucionário. Mas sim, resistências no plural, que são casos únicos: possíveis, necessárias, improváveis, espontâneas, selvagens, solitárias, planejadas, arrastadas, violentas, irreconciliáveis, prontas ao compromisso, interessadas ou fadadas ao sacrifício; por definição não podem existir a não ser no campo estratégicos das relações de poder. (...) Elas não são o outro termo nas relações de poder; inscrevem-se nestas relações como interlocutor irredutivel" (Foucault 1979b, p. 91).

Um outro aspecto capital da analítica do poder é a adoção do modelo da guerra à inteligibilidade das relações de poder. Assim, "o poder é guerra, guerra prolongada por outros meios" (Foucault, 1979a, p. 176). É em termos de confronto e de combate com suas táticas e estratégias, onde se tem "por princípio cumular vantagens e multiplicar benefícios” (Foucault, 1980, p. 37), que melhor podemos compreender o modo pelo qual se desdobra e articula a extensa rede de poder que atravessa o corpo social. A base das relações de poder seria o confronto belicoso das forças sociais em antagonismo constante, já que tais relações implicam pelos próprios princípios teóricos desta noção (como já brevemente descrito nos parágrafos anteriores) uma rebeldia e insurgência constantes por parte daqueles que estão submetidos às relações de poder.

Foucault ao utilizar-se do paradigma da guerra tenta escapar das insuficiências da análise tradicional do poder, onde em geral, a reflexão se dá em termos de Direito e soberania ${ }^{5}$, como já destacado anteriormente, os quais, via de regra, caíam numa perspectiva onde o poder se exerceria basicamente através de aspectos negativos - proíbe, obstaculiza, constrange, etc. - e sob a forma da lei. A utilização deste modelo se inscreve na preocupação de Foucault de desenvolver o instrumental teórico necessário à uma nova análise do poder. Ele constata e afirma a inexistência de ferramentas conceituais aptas a compreender a dinâmica das relações de poder ${ }^{6}$. Esclareça-se, entretanto, que Foucault não se coloca na posição de descobridor do modelo da guerra como forma de inteligibilidade das relações sociais e de poder e, ainda mais, ele não deixa de mencionar a sua constante utilização — talvez a hipótese mais fre- mente reconhecido e mantido até o fim como uma pessoa que age; e que, em face de uma relação de poder, todo um campo de respostas, reações, resultados, e possíveis invenções seja aberto.

${ }^{5}$ Como indica Foucault "Para levar a cabo a análise concreta das relações de poder, deve-se abandonar o modelo jurídico da soberania. Com efeito, este modelo pressupõe o indivíduo como sujeito de direitos naturais ou poderes primitivos; ele se coloca como objetivo de dar conta da gênese ideal do Estado; enfim, ele faz da lei a manifestação fundamental do poder" (1974-82, curso $75 / 76$, p. 361$)$.

${ }^{6}$ Em passagem esclarecedora Foucault comenta este ponto: “(...) parece-me que a história e teoria econômica forneceram (um bom) instrumento para as relações de produção; que a linguística e a semiótica ofereceram instrumentos para o estudo das relações de significação; mas para as relações de poder não há instrumentos para estudar. Nós temos recorrido somente a maneiras sobre o poder baseadas em modelos legais, isto é: $\mathrm{O}$ que legitima o poder? Ou então recorremos ao modo de pensar baseados nos modelos institucionais, isto é: O que é Estado?" (grifos meus) (Foucault, 1982. p. 209). 
qüente quando se procurou evitar o modelo legal —, todavia, ele critica a má utilização deste modelo, apontando para a necessidade de um desenvolvimento deste tipo de análise. Neste sentido:

"O que me parece certo é que, para analisar as relações de poder, só dispomos de dois modelos: o que o Direito nos propõe (poder como lei, proibição, instituição) e o modelo guerreiro ou estratégico em termos de relações de forças. O primeiro foi muito utilizado e mostrou, acho eu, ser inadequado: sabemos que o Direito não descreve o poder. O outro sei bem que também é muito usado. Mas fica nas palavras: utilizam-se noções pré-fabricadas ou metáforas ('guerra de todos contra todos', 'luta pela vida') ou ainda esquemas formais (as estratégias estão em moda entre alguns sociólogos e economistas, sobretudo americanos). Penso que seria necessário tentar aprimorar esta análise das relações de força” (Foucault, 1979a, p. 241).

Enfim, nesta primeira parte, foram destacadas algumas das características da concepção de Foucault a respeito do poder. Certamente um assunto como este poderia ser tratado de forma mais detalhada e exaustiva. Aqui foi merecedor apenas de uma primeira abordagem. Na segunda parte deste artigo o enfoque será distinto, procurando descrever algumas modificações observadas ao longo dos anos 70 nas investigações de Foucault.

\section{O deslocamento da noção de poder em Michel Foucault}

Nesta segunda parte a análise se dará em outro eixo, privilegiando a dimensão temporal. Ao discutirmos alguns outros aspectos da noção de poder de Foucault, ficará patente que certas preocupações estarão mais presentes em um ou outro momento da pesquisa genealógica. Assim, nossas considerações referir-se-ão a certas características desta discussão relacionadas aos períodos onde se encontram mais enfatizadas. Por exemplo, segundo a nossa análise, a questão do poder disciplinar se apresentará como absolutamente central de 1973 a 1975, já a discussão sobre a governabilidade será destacada a partir de 1978 e, quanto ao bio-poder, sua problematização recairá no período de 76/77. Ao acompanhar a trajetória da temática do poder ao longo dos anos 70, observando a maneira como certos aspectos serão ressaltados em um período, para posteriormente cederem lugar a uma discussão um pouco distinta, nos parece que podemos afirmar a existência de um deslocamento na noção de poder de Foucault.

Ora, antes mesmo de iniciarmos a análise desta segunda parte, onde procuraremos detalhar este deslocamento da noção de poder - em especial a passagem para a questão da governamentalidade — poderíamos afirmar que talvez este deslocamento seja quase um corolário da forma de Foucault traba- 
MAIA, Antônio C. Sobre a analítica do poder de Foucault. Tempo Social; Rev. Sociol. USP, S. Paulo, 7(1-2): 83-103, outubro de 1995.

lhar. Durante toda a sua carreira ficou claro um estilo onde as pesquisas, com os conseqüentes desdobramos teóricos, avançam ao sabor do material empírico trabalhado, animadas por uma infatigável curiosidade. Esta marca do método de Foucault explica o caráter, em certo sentido, deslizante de seu trabalho. Ademais, as sucessivas transformações na sua obra ficam justificadas a partir de um dos cuidados principais de todo o seu trajeto filosófico, sintetizado em uma das suas últimas entrevistas: "São as coisas gerais que surgem em último lugar. É o preço e a recompensa de todo o trabalho em que as peças teóricas se elaboram a partir de um certo domínio empírico" (Foucault, 1977, p. 76).

Por outro lado, este deslocamento/modificação no percurso de Foucault no tocante à questão de poder pode ser encarado como um progressivo aperfeiçoamento do arsenal teórico a partir dos domínios empíricos trabalhados. Ou melhor, na medida em que Foucault ia se aprofundando nas pesquisas em torno das formas pelas quais, na Civilização Ocidental, se estruturam as diversas práticas (e as instituições que lhe eram e são correlatas) que veiculam e fazem funcionar as relações de poder, foi paulatinamente desenvolvendo diferentes categorias, para dar conta do material analisado. Como destacado no parágrafo anterior, no trabalho de Foucault não há uma intuição primeira que o analista procura comprovar através dos exemplo oriundos de sua interpretação histórica. Para Foucault, o dado empírico impõe a sua positividade, obrigando a uma posterior conceitualização que acompanhe sempre os avanços da pesquisa. Neste sentido, ao mapearmos os desdobramentos de seu trabalho ao longo dos anos 70, destacaremos as diversas categorias utilizadas para identificar e entender a dinâmica do funcionamento do poder. Assim, poder disciplinar, bio-poder, governamentalidade, etc., são diferentes tecnologias de poder postas em funcionamento - às vezes com hegemonia de uma, mas em geral coexistindo em complexos arranjos na sociedade ocidental a partir do século XVI.

\section{O bio-poder (poder disciplinar e bio-política)}

A preocupação com a identificação e análise do processo pelo qual se dá a tomada do poder sobre os corpos, na sociedade ocidental, ocupará o centro das pesquisas de Foucault a partir de 1972/73. A sua analítica procurará retraçar a trajetória das diversas tecnologias de poder que se desenvolveram no Ocidente a partir do final do século XVI até constituírem a sofisticada estrutura de poder que envolve o homem contemporâneo. Estes diversos processos que acarretaram uma progressiva organização da vida social, através de meticulosos rituais de poder que tem como objetivo o corpo, se deram através do que Foucault caracterizou como bio-poder. O estudo desta problemática se encontrará privilegiado nos dois livros de Foucault dos anos 70, Vigiar e punir a Vontade de saber cumprindo um dos projetos avançados no texto programático desta fase do seu trabalho: Nietzsche, a genealogia e a história. Desta forma, "A genealogia (...) está portanto no ponto de articulação do corpo com a história. Ela deve mostrar o corpo inteiramente marcado, 
e a história arruinando o corpo" (Foucault, 1979a, p. 22).

Como Foucault afirma no início de Vigiar e punir: “(...) o corpo também está diretamente mergulhado num campo político; as relações de poder têm alcance imediato sobre eles; elas o investem, o marcam, o dirigem, o supliciam, sujeitam-no a trabalhos, obrigam-no a cerimônias, exigem-lhe sinais" (Foucault, 1977, p. 28). Por conseguinte, devemos ter em mente que a genealogia do poder terá o corpo como um objeto privilegiado de análise e preocupação. Quem destaca esta questão é François Ewald, no texto que apresenta a discussão mais profunda sobre Vigiar e punir, Anatomie et corps politique:

“A genealogia é física e microfísica do poder. Se ela
descobre os corpos de poder, ela os vê sempre apli-
cados sobre outros corpos. Sobre o que um corpo
poderia agir senão sobre um outro corpo? A
genealogia adota o ponto de vista dos corpos, aque-
le do supliciado, adestrado, marcado, mutilado, de-
composto, obrigado, constrangido; aquele dos cor-
pos que se repartem, que se separam e que se reú-
nem. A lei de exercício do poder é aquela do corpo a
corpo, de corpos que se aplicam sobre outros corpos
para educá-los, fabricá-los; de corpos que resistem
a esta aplicação. A genealogia descreveu os efeitos:
produção de almas, produção de idéias, de saber, de
moral, ou seja, produção de poder que se reconduz
sobre outras formas. O poder é ao mesmo tempo cau-
sa e efeito” (Ewald, 1975, p. 1237).

A atuação do poder sobre os corpos que Foucault chamara de biopoder tem que ser percebida nas suas especificidades. Vale dizer, sob esta denominação, Foucault designará principalmente dois níveis de exercício do poder: de um lado, as técnicas que têm como objetivo um treinamento "ortopédico" dos corpos, as disciplinas e o poder disciplinar; de outro lado, o corpo entendido como pertencente a uma espécie (a população) com suas leis e regularidades. O primeiro nível de análise se encontra tratado predominantemente em Vigiar e punir, quanto ao outro, na Vontade de saber, veremos esboçados os princípios desta análise, que posteriormente serão retomados nos Cursos do Collège de France de 77/78. Estes dois planos trabalhados na analítica do poder são destacados por Pasquale Pasquino e Alexandre Fontana numa questão endereçada a Foucault na entrevista Verdade e poder:

"Ter-se-ia, por um lado, uma espécie de corpo global, molar, o corpo da população, junto com toda uma série de discursos que lhe concernem e, então, por outro lado e abaixo, os pequenos corpos, dóceis, corpos individuais, os micro corpos da disciplina. Mesmo que se esteja no início de pesquisas neste 
MAIA, Antônio C. Sobre a analítica do poder de Foucault. Tempo Social; Rev. Sociol. USP, S. Paulo, 7(1-2): 83-103, outubro de 1995.

ponto, poder-se-ia dizer como se vê a natureza das relações (caso existentes) as quais são engendradas entre estes diferentes corpos: o corpo molar da população e os micro-corpos dos indivíduos" (Foucault, 1980a, p. 124).

Acreditamos que a identificação destes dois níveis - corpo molar da população e microcorpo dos indivíduos, como denominam Fontana e Paquino - marque também uma modificação no tratamento de Foucault no tocante ao poder. Observa-se que, embora estas tecnologias de poder estejam profundamente articuladas e entrelaçadas no mundo contemporâneo, além de terem origens distintas, elas vão sendo paulatinamente identificadas ao longo do trabalho de Foucault nos anos 70. Assim, do momento em que o corpo passa a assumir posição de relevo no seu trabalho, em 73, até a publicação de Vigiar e punir em 75, o destaque residirá no poder disciplinar. A partir da publicação da Vontade de saber em 76, abrir-se-á uma outra área de pesquisa, focalizando o corpo molar da população. Neste momento, Foucault fala da bio-política ou do bio-poder. Posteriormente este último termo será empregada em um sentido mais amplo, dando conta também do poder disciplinar, posto que em ambos os casos o objeto de atuação do poder é o corpo e a vida humana (se bem que atingidos de maneira distintas). Assim, de agora em diante faremos neste trabalho uma pequena subdivisão: primeiramente, algumas observações sobre o poder disciplinar, para depois nos determos nos aspectos da atuação do poder sobre a população. Esclareça-se que quanto a este segundo aspecto nos referimos a ele como bio-poder, observando a terminologia empregada na Vontade de saber - texto fundamental à discussão deste particular, apesar do já exposto anteriormente quanto à utilização posterior mais ampla desta categoria.

Ao constatar que "houve, durante a época clássica, uma descoberta do corpo como objeto e alvo do poder" (Foucault, 1977, p. 125). Foucault procurou identificar as formas e procedimentos múltiplos pelos quais se deu esta "ocupação" dos corpos pelo poder. Por conseguinte, a constituição de um arsenal teórico que possibilitasse a análise e, também, a identificação do nível onde se dá este encontro poder/corpos ${ }^{7}$ marcará as preocupações de Foucault, especialmente no fim de 73, em 74, e tratado com mais detalhe em Vigiar e punir. O que o interessará, entre outras coisa, será destacar que mecanismos, táticas e dispositivos serão progressivamente utilizados pelo poder na época clássica e como alguns destes mecanismos, com certas transformações, permaneceram até os nossos dias, integrando a enorme parafernália do poder que envolve a sociedade contemporânea. Entre estes mecanismos se encontram as disciplinas, isto é, "Esses métodos que permitem o controle minucioso das operações do corpo, que realizam a sujeição constante de suas forças e lhes impõe uma relação de docilidade-utilidade" (Foucault, 1977, p. 126).

O que observa Foucault é que a partir do fim do século XVII, ao longo do século XVIII e especialmente no início do século XIX, desenvolveu-
7 No tocante a este aspecto, e apontando para este nível de análise, que obrigaria a construção de uma física do poder, destaca Foucault: "A transformação da penalidade não depende apenas de história dos corpos, porém, mais precisamente, de uma história das relações entre o poder político e os corpos. A coerção sobre o corpo, o seu controle, seu assujeitamento, a maneira pela qual ela os dobra, os fixa, os utiliza está no princípio da mudança estudada. Seria necessário escrever uma 'Física' do poder, e mostrar quanto ela foi modificada em relação a suas formas anteriores, no começo do século XIX, quando do desenvolvimento das estruturas estatais" (citado em Marietti, 1977). 
MAIA, Antônio C. Sobre a analítica do poder de Foucault. Tempo Social; Rev. Sociol. USP, S. Paulo, 7(1-2): 83-103, outubro de 1995.

${ }^{8}$ Em relação a esta nova realidade políticoeconômica que demandava a utilização das tecnologia disciplinar. "Esclarece Foucault:" Esse triplo objetivo da disciplina responde a uma conjuntura histórica bem conhecida. É por um lado a grande explosão demográfica do século XVIII: aumento da população flutuante, (fixar é um dos primeiros objetivos da disciplina; é um processo de antinomadismo); mudança da escala quantitativa dos grupos que importa controlar ou manipular (...). O outro aspecto da conjuntura é o crescimento do aparelho de produção, cada vez mais extenso e complexo, cada vez mais custoso também e cuja rentabilidade urge fazer crescer. O desenvolvimento dos modos disciplinares de proceder responde a esses dois processos ou antes sem dúvida à necessidade de ajustar sua correção "(Foucault, 1977).

${ }^{9}$ Como destaca Foucault, em esclarecedora passagem: "A disciplina é uma técnica de exercício de poder que foi, não inteiramente inventada, mas elaborada em seus princípios fundamentais durante o século XVIII. Historicamente as disciplinas existiam a muito tempo, na Idade Média e mesmo na antigüidade. Os mosteiros são um exemplo de região, domínio no interior do qual reinava o sistema disciplinar. A escravidão e as gran- se e estruturou-se toda uma nova tecnologia de aproveitamento/utilização da força dos corpos. Tal tecnologia se organizará basicamente em torno da disciplina, isto é, "o processo técnico unitário pelo qual a força do corpo é com o mínimo de ônus reduzida como força política, e maximizada como força útil" (Foucault, 1977, p. 194). Ligada aos imperativos econômicos e políticos de uma nova ordem que se impunha ${ }^{8}$, as disciplinas - técnicas já conhecidas na civilização ocidental ${ }^{9}$, como por exemplo nos conventos, nas oficinas e nas legiões romanas - passam a ser utilizadas maciçamente. Fábricas, escolas, hospitais, hospícios, prisões, etc., instituições fundamentais ao funcionamento da sociedade industrial capitalista, se estruturaram e tem como lógica de funcionamento as técnicas e táticas oriundas deste processo de disciplinarização. Por conseguinte, fica claro que nesta conjuntura se articula uma nova relação entre o poder e os corpos, como ele explica:

\section{"O momento histórico das disciplinas é o momento} em que nasce uma arte do corpo humano, que visa não unicamente ao aumento de suas habilidades, nem tampouco aprofundar sua sujeição, mas a formação de uma relação que no mesmo mecanismo o torna tanto mais obediente quanto mais útil, e inversamente. Formam-se então uma política das coerções que são um trabalho sobre o corpo, uma manipulação calculada de seus elementos, de seus gestos, de seus comportamentos. O corpo humano entra numa maquinaria de poder que o esquadrinha, o desarticula e o recompõe. Uma "anatomia-política": que é também igualmente uma mecânica do poder, está nascendo (...) A disciplina fabrica assim corpos submissos, exercitados, corpos 'dóceis'”, (Foucault, 1977, p. 127).

Neste momento de sua obra, há o privilégio da análise das técnicas de poder que se centram no corpo; como que tratando-o como máquina, adestrando-o, amplificando a sua utilização, aperfeiçoando a extração do trabalho, integrando-o ao novo circuito da produção instaurado a partir do século XVIII. Neste sentido as análises de Vigiar e punir, em especial ao destacar a questão do panoptismo, isto é: "o princípio geral de uma nova 'anatomiapolítica', cujo objeto e fim não são as relações de soberania mas as relações de disciplina" (Foucault, 1977, p. 183) marcam a emergência de uma nova forma de atuação do poder sobre os corpos: o poder disciplinar. O panóptico representa o modelo por excelência - utilizado nas prisões, fábricas, escolas, hospitais, etc. - desta tecnologia de poder que se impõe ao longo do século XIX, que tem "por pura função impor uma tarefa ou uma conduta qualquer a uma multiplicidade de indivíduos, desde que ela seja pouco numerosa e o espaço limitado, pouco extenso" (Deleuze, 1986, p. 79).

A atuação do poder disciplinar apresenta aspectos distintos da ma- 
MAIA, Antônio C. Sobre a analítica do poder de Foucault. Tempo Social; Rev. Sociol. USP, S. Paulo, 7(1-2): 83-103, outubro de 1995.

neira pela qual se articulava o poder político na Idade Média, onde "o poder funcionava essencialmente por meio de símbolos e taxas. Sinais de lealdade ao senhor feudal, ritos e cerimonias entre outros, e taxas, na forma de impostos, pilhagens, guerras e etc" (Foucault, 1980a, p. 125). Diferentemente, na época clássica começou a se estruturar uma tecnologia de poder - que só estará plenamente desenvolvida no final do século XVIII - que repousou em outras bases. A tecnologia que funcionou em torno do poder disciplinar se sustentará mais em uma ação sobre os corpos e seus atos do que sobre os produtos retirados da terra. $\mathrm{O}$ fundamental é colocar em operação mecanismos que possibilitem uma extração de tempo e trabalho dos corpos, relegando a um segundo plano as velhas formas de atuação que tinham na extração imediata de bens e riquezas seu objetivo primordial. Este novo tipo de poder se exerce supondo mais um sistema minucioso de coerções materiais do que a figura de um príncipe soberano.

Por fim, para que se possa perceber melhor as características da disciplina, cabe destacar que ela “(...) nem é um aparelho, nem uma instituição: ela funciona como uma rede que os atravessa sem se limitar a suas fronteiras; é uma técnica, um dispositivo, um mecanismo, um instrumento de poder" (Machado, 1982, p. 194). Assim, a disciplina se exerce em uma série de espaços do corpo social, tendo como princípios básicos os seguintes aspectos ela é uma arte de distribuição espacial dos indivíduos; a disciplina exerce seu controle não sobre o resultado de uma ação, mas sobre seu desenvolvimento; ela é uma técnica de poder que implica uma vigilância perpétua e constante dos indivíduos e ela é também um controle do tempo.

Eis que, se esta discussão sobre a relação do poder sobre os corpos e a caracterização do poder disciplinar estão nitidamente presentes no período de 74/75, com o lançamento da Vontade de saber, em 76, pode-se falar de uma mudança. Foucault não abandonará a idéia do poder disciplinar, mas a articulará com uma outra tecnologia, que será destacada nas análises dos anos subsequientes, o bio-poder, que se distinguirá do poder disciplinar em alguns aspectos, entre eles o fato de que esta nova forma de poder considerará "uma outra função (...) gerar e controlar a vida dentro de uma multiplicidade desde que ela seja numerosa (população), e o espaço estendido ou aberto" (Deleuze, 1986, p. 79).

Embora o objetivo das análises ainda seja o corpo, agora é o corpomolar da população, que será ressaltado. Assim, dentro da nossa análise, destacaríamos a ênfase dada por Foucault no seu trabalho, dos anos 76 a 78, na análise desta tecnologia própria às sociedades ocidentais: o bio-poder. Como ele afirma, no final da Vontade de saber (distinguindo o poder disciplinar do bio-poder):

"O segundo, que se formou um pouco mais tarde, por volta da metade do século XVIII, centrou-se no corpo-espécie, no corpo transpassado pela mecânica do ser vivo e como suporte dos processos biológi- des empresas escravistas existentes nas colônias espanholas, inglesas, francesas e holandesas, etc., eram modelos de mecanismos disciplinares. Pode-se recuar até a Legião Romana e lá também encontrar um exemplo de disciplina. Os mecanismos de disciplina são, portanto, antigos, mas existiam em estado isolado, fragmentado, até o século XVII e XVIII, quando o poder disciplinar foi aperfeiçoado como uma nova técnica de gestão dos homens. Fala-se, freqüentemente, das invenções técnicas do século XVIII - as tecnologias químicas, metalúrgica, etc. - mas erroneamente, nada se diz da invenção técnica dessa nova maneira de gerir os homens, controlar suas multiplicidades, utilizá-las ao máximo e majorar o efeito útil de seu trabalho e sua atividade, graças a um sistema de poder suscetível de controlá-los. Nas grandes oficinas que começam a se formar, no exército, na escola, quando se observa na Europa um grande processo de alfabetização, aparecem essas novas técnicas de poder, que são uma grande invenção do século XVIII" (Foucault, 1979a, p. 105). 
MAIA, Antônio C. Sobre a analítica do poder de Foucault. Tempo Social; Rev. Sociol. USP, S. Paulo, 7(1-2): 83-103, outubro de 1995.

${ }^{10}$ Este novo processo de atuação do poder se dará, como diz Foucault, com "a entrada dos fenômenos próprios à vida da espécie humana na ordem do saber e do poder no campo das técnicas políticas" (Foucault, 1979b, p.133). Como ele afirma em outra passagem, a população vai passar a ser, na segunda metade do século XVIII, um objeto privilegiado de atuação do poder: "Os traços biológicos de uma população tornam-se fatores relevantes para a administração econômica e torna-se necessário organizar ao seu redor um aparato que vai afirmar não apenas a sua sujeição mas também o crescimento constante de sua utilidade" (Foucault, 1980b, p. 172).

${ }^{11}$ Como já afirmado, alguns traços do bio-poder são expostos no final da Vontade de saber. No tocante aos cursos do Collège de France, as referências não são muito numerosas também. O Curso 75/76 tratou, resumidamente, da questão da utilização do modelo guerreiro como possibilidade de inteligibilidade das relações de poder. Em 76/77 não houve curso. É no curso de 78/ 79 que basicamente temos algumas informações já que, no curso de 78/79, Foucault privilegiou a análise em termos da Governamentalidade e no estudo da racionalidade liberal. Assim, no curso de 77/78, há cos; a proliferação, os nascimentos e a mortalidade, o nível de saúde, a duração da vida, a longevidade, com todas as condições que podem fazê-los variar; tais processos são assumidos mediante toda uma série de intervenções e controles reguladores: uma biopolítica da população (...) A velha potência da morte em que se simbolizava o poder soberano é agora, cuidadosamente, recoberta pela administração dos corpos e pela gestão calculista da vida" (Foucault, 1979b, p. 131).

Desta forma, a partir da articulação da existência de um novo objeto à atuação do poder - a população, com suas regularidades: taxa de natalidade, mortalidade, longevidade, etc. ${ }^{10}$ - estrutura-se toda uma nova tecnologia do poder. Esclareça-se, contudo, que esta nova tecnologia não implica o abandono da idéia e utilização do poder-disciplinar; pelo contrário, as duas - poder-disciplinar e bio-poder - se integram para um controle/gestão mais efetivo dos corpos. Apenas uma nova área e forma de atuação do poder nas sociedades ocidentais é posto a nu pela análise de Foucault com a noção de bio-poder. A preocupação da análise desta realidade é marcante nos anos de 76 a 78 . Se temos somente uma breve descrição do bio-poder no capítulo quinto da Vontade de saber, os cursos do Collège de France neste período fornecem indicações sobre esta problemática.

Entretanto, pode-se observar que a questão do bio-poder parece ter sido a menos trabalhada por Foucault: à exceção dos textos já mencionados, é escassa a referência a esta discussão ${ }^{11}$. Contudo, ainda poderíamos afirmar a existência de uma mudança de ênfase no trabalho de Foucault, posto que o nível de atuação do poder focalizado - diferentemente do poder disciplinar - se apresenta em outro plano. Neste momento o objeto de análise é a forma de poder que "se situa e exerce ao nível da vida, da espécie, da raça e dos fenômenos maciços de população" (Foucault, 1979b, p. 129).

Cabe precisar, entretanto, o seguinte: Foucault não afirma que foi no século XVIII que pela primeira vez, a população surgiu como objeto de atuação do poder ${ }^{12}$. Já na antiguidade clássica, em Roma, observou-se a existências de políticas públicas visando à regulamentação da dinâmica da populacional, através de leis estimulando casamento, isenção de impostos para famílias numerosas, etc. Porém, no século das luzes, a população começa a ser estudada, analisada e esquadrinhada por uma série de políticas que tem como suporte as ciências do homem que se constituem neste século, como a demografia e a medicina social. Tais políticas procuram estabelecer um controle e gestão mais efetivo dos membros de uma população, diferenciando-se das políticas que até então tinham como escopo atingí-la, as quais, em geral, caracterizavam-se por uma atuação dispersa, sem continuidade e deixando vários recantos deste conjunto intocados. Precisando as origens e características desta tomada de corpo-molar da população como objeto de poder, 
MAIA, Antônio C. Sobre a analítica do poder de Foucault. Tempo Social; Rev. Sociol. USP, S. Paulo, 7(1-2): 83-103, outubro de 1995.

Foucault afirma:

"Qual é a base para esta transformação? Genericamente, pode-se dizer que ela se relaciona com a preservação e conservação da 'força de trabalho'. Mas, indubitavelmente, o problema é mais amplo. Ele indiscutivelmente se refere aos efeitos político-econômicos da acumulação de homens. $O$ grande crescimento demográfico do século XVIII na Europa Ocidental, a necessidade de coordenação e de integração ao aparato de produção e a urgência de controlálo, com mecanismos de poder mais sofisticados $e$ adequados, possibilitaram a emergência da 'população', (com suas variedades numéricas de espaço e cronologia, longevidade e saúde), emergisse não só como problema, mas como um objeto de observação, análise, intervenção, modificação, etc. Um projeto de tecnologia da população começa a ser desenhado: estimativas demográficas, o cálculo de pirâmides etárias, diferentes expectativas de vida e níveis de mortalidade, estudos das recíprocas relações entre crescimento da população e crescimento da riqueza, medidas de incentivo ao casamento e procriação, desenvolvimento de formas de educação e treinamento profissional" (Foucault, 1980b, p. 171).

Possivelmente esta discussão do bio-poder seja melhor percebida se encarada como uma espécie de transição entre as pesquisas de Vigiar e punir e uma temática que marcará os seus últimos anos de trabalho: a questão do governo. Esta perspectiva se abre a partir do que Foucault afirma no início do Curso do Collège de France, de 77/78:

"o curso tratou da gênese de um saber político que colocou, no centro de suas preocupações, a noção de população e os mecanismos suscetíveis de assegurar a sua regulação. Passagem de um 'Estado territorial' a um 'Estado de população'. Sem dúvida não se trata de uma substituição mas de uта mudança de acentuação, e da aparição de novo problema e de novas técnicas. Para seguir esta gênese, foi assumido como fio condutor a noção de governo" (Foucault, 1974-82, p. 445).

Neste instante fica nítida aquela que parece ser a modificação mais radical dentro da genealogia do poder. Como já destacamos anteriormente, é clara a passagem, nesta data da discussão sobre o poder para outros termos, analisados até o final da obra de Foucault a partir da questão do governo. Esclareça-se, antes mesmo de nos determos com um pouco mais de atenção uma esclarecedora passagem acerca desta questão da população, objeto do bio-poder: "Assim, começa aparecer (...) o problema da população. Esta não á concebida como um conjunto de sujeitos de direito, nem como um grupo de braços destinados ao trabalho; ela é analisada como um conjunto de elementos que de um lado se aproxima do regime geral dos seres vivos (a população depende então da espécie 'humana': noção nova à época, distinta da noção de 'gênero humano') e de outro, pode dar lugar às intervenções concentradas (por intermédio das leis, mas também das mudanças de atitude, da maneira de fazer e de viver que podem ser obtidas pelas 'campanhas')" (Foucault, 1974-82, curso 77/78, p. 447-448).

${ }^{12}$ Como explica Foucault: "Certamente o problema da população sob a forma: 'seremos nós muito numerosos, não suficientemente numerosos? , há muito tempo colocado, há muito tempo que se dá a ele soluções legislativas diversas: impostos sobre os celibatários, isenção de impostos para as famílias numerosas, etc. Mas, no século XVIII, o que é interessante, em primeiro lugar, é uma generalização destes problemas: todos os aspectos do problemas população começam a ser levados em conta (epidemias, condições de habitat, de 
MAIA, Antônio C. Sobre a analítica do poder de Foucault. Tempo Social; Rev. Sociol. USP, S. Paulo, 7(1-2): 83-103, outubro de 1995.

higiene, etc.) e a se integrar no interior de um problema central. Em segundo lugar, vêse a este problema novos tipos de saber: aparecimento da demografia, observações sobre a repartição das epidemias, inquéritos sobre as amas de leite e as condições de aleitamento. Em terceiro lugar, o estabelecimento de aparelhos de poder que permitiam não somente a observação, mas a intervenção direta e manipulação de tudo isto. Eu diria que neste momento começa algo que se pode chamar de poder sobre a vida, enquanto antes só havia vagas incitações descontínuas para modificar uma situação que não se conhecia bem" (Foucault, 1979a, p. 234-275). sobre este tema, que governo não deve ser entendido da maneira usual como uma burocracia ou grupo de pessoas à frente da gestão da coisa pública, ou a atividade exercida por aqueles que conduzem a máquina estatal (entre outros significados), mas sim no seguinte sentido:

"Esta palavra (Governo) deve ser compreendida no sentido mais amplo que tinha no século XVI. 'Governo'não se referia apenas a estruturas políticas ou a administração dos Estados; antes, designava o modo pelo qual a condução de indivíduos ou grupos deveria ser orientada: o governo das crianças, das almas, dos bens, das famílias, dos doentes. Ele cobria não apenas as formas legitimamente constituídas de sujeição política ou econômica mas também maneiras de agir destinadas a atuar sobre as possibilidades de ação das outras pessoas. Governar, neste sentido, seria estruturar o possivel campo de ações dos outros" (Foucault, 1982, p. 221).

\section{A governamentalidade}

Talvez no seu texto mais importante de 1978, o debate com os historiadores acerca de Vigiar e punir, publicado no livro L'impossible prison, Foucault marca a significação da questão do governo na sua obra. Assim, "para dizer as coisas claramente: meu problema é saber como os homens se governam (eles mesmos e os outros)" (Foucault, 1980a). Por conseguinte, o poder passa a ser trabalhado em uma outra perspectiva; é o governo de si e o governo dos outros - que obviamente pressupõem e estão inscritos nas relações de poder - que constituirá o cerne do trabalho de Foucault até a sua morte.

Um texto central nesta perspectiva é a 'Governamentalidade', de 1978. Esta aula no Collège de France lança os princípios deste tipo de análise que lida com "o problema de como ser governado, por quem, até que ponto, com qual objetivo, com que método, etc." (Foucault, 1979a, p. 278). Com efeito, Foucault faz o inventário do surgimento, a partir do século XVI, de toda a literatura - estreitamente vinculada ao príncipe de Maquiavel, quer por oposição, quer por recusa - que trata da arte de governo. Esta teoria não se resumiu a mero exercício acadêmico, pois "a teoria da arte de governar esteve ligada desde o século XVI ao desenvolvimento do aparelho administrativo da monarquia territorial: aparecimento dos aparelhos de governo" (Foucault, 1979a, p. 285). Por outro lado, a arte do governo rompe com a tradição da teoria jurídica da soberania - fundamentada no governo do território, e afirmando que "o governo é uma correta disposição das coisas" (Foucault, 1979a, p. 282).

Entretanto, nos parece importante frisar que a arte de governar se articula em torno de um tema importante à análise política: a Razão de Esta- 
MAIA, Antônio C. Sobre a analítica do poder de Foucault. Tempo Social; Rev. Sociol. USP, S. Paulo, 7(1-2): 83-103, outubro de 1995.

do, e aí, não no sentido moderno do termo, mas naquele relacionado à racionalidade da atuação estatal. Assim este tema, pesquisado por Foucault no final dos anos 70, não deve ser confundido com a idéia de razão de Estado, como aquilo que justifica o desrespeito das regras formais do jogo político em nome de um interesse superior, onde está, em geral, presente o arbítrio e a violência. O sentido dado por Foucault se articula com uma noção de arte de governo, tematizada freqüentemente ao longo do século XVII e início do XVIII. Como ele explica esta distinção:

"Esquematicamente se poderia dizer que a arte de governar encontra, no final do século XVI e no início do século XVII, uma primeira forma de cristalinização, ao se organizar em torno do tema de uma razão de Estado. Razão de Estado hoje entendida não no sentido pejorativo e negativo que lhe é dado (ligado à infração dos princípios do Direito, da eqüidade, ou da humanidade por interesses exclusivos dos Estados), mas no sentido positivo e pleno: $o$ Estado se governa segundo as regras racionais que lhe são próprias, que não se deduzem nem das leis naturais ou divinas, nem dos preceitos da sabedoria ou da prudência: o Estado, como a natureza, tem sua racionalidade própria, ainda que de outro tipo. Por sua vez, a arte de governo em vez de fundar-se em regras transcendentais ou em um ideal filosóficomoral, deverá encontrar sua racionalidade naquilo que constitui a sua racionalidade própria" (Foucault, 1979a, p. 286).

Esta discussão de Foucault a respeito da Governamentalidade ocorre no momento em que se dá a mudança mais drástica no projeto genealógico. Se durante os anos 70 as preocupações estiveram concentradas em reflexões de caráter eminentemente político, de 78 até a sua morte em 84 a ética ocupará, basicamente, a sua atenção. Neste sentido as pesquisas sobre a governamentalidade marcam uma transição: do governo dos outros - e aqui incluídas todas as investigações sobre o poder - para o governo de si. Assim, é o continente da Ética, o tema dos dois últimos livros de Foucault, $O$ uso dos prazeres e $O$ cuidado de si. Com efeito, o estudo da Antigüidade não privilegiará os mecanismos de constrangimento, nem as insidiosas técnicas utilizadas à submissão dos corpos e almas. As pesquisas acerca da maneira como no século IV a.C., na Grécia, e no século I e II d.C., em Roma, as condutas sexuais eram objeto de ponderações de natureza ética, se encontram em um cenário bem diferente das problematizações anteriores de Foucault. Há a passagem de um exame das práticas empregadas no governo de si. Não se estudam mais os efeito do poder no processo de subjetivação dos sujeitos, mas sim as técnicas usadas no governo de si. Talvez esta passagem para um universo tão 
diferente de investigações explique o fato de que Foucault não se deteve por muito tempo nas investigações atinentes à Governamentalidade. Além do texto já mencionado acerca desta questão, temos poucas referências. Os anais do Curso do Collège de France do ano de 77/78 destacam também esta investigação:

"Em seguida foi analisado, a respeito de alguns de seus aspectos, a formação de uma 'governamentalidade política., isto é, a maneira pela qual um conjunto de indivíduos se encontra implicado, de maneira cada vez mais marcada, no exercício do poder soberano. Estas transformações importantes são assimiladas nas diferentes 'artes de governo' que foram redigidas, no fim do século XVI. Ela é ligada sem dúvida à emergência da 'Razão de Estado'. Se passa de uma arte de governar cujos princípios eram pedidos emprestados das virtudes tradicionais ( sabedoria, Justiça, liberdade, respeito às leis divina e aos costumes humanos) ou das habilidades comuns (prudência, decisões refletidas, cuidado de estar cercado dos melhores conselheiros) para uma arte de governar cuja racionalidade tem princípios e seu domínio específico de aplicação no Estado. A 'Razão de Estado' não é o imperativo a partir do qual se pode ou se deve 'balançar' todas as outras regras; [ a razão do Estado] é a nova matriz de racionalidade segundo a qual o príncipe deve exercer sua soberania governando os homens. Se está longe da virtude soberana da justiça, longe também desta virtude que é aquela do herói de Maquiavel" (Foucault, 197482, p. 446).

Por fim, deve-se observar que este nosso trabalho procurou apenas alinhavar algumas considerações sobre as problematizações foucaultianas a respeito do poder. O tema merece uma atenção e tratamento mais cuidadoso.

Fica aberto o caminho para uma pesquisa mais minudente e o convite à leitura de um dos pensadores mais instigantes de nosso século.

Recebido para publicação em junho/1995 
MAIA, Antônio C. Sobre a analítica do poder de Foucault. Tempo Social; Rev. Sociol. USP, S. Paulo, 7(1-2): 83-103, outubro de 1995.

MAIA, Antônio C. About the Foucault's analytic of power. Tempo Social; Rev. Sociol. USP, S. Paulo, 7(1-2): 83-103, october 1995.

ABSTRACT: To understand the way social relations are structured, in particular the unequal relations of obedience and domination which justify both autority and the nature of of political obligation, has been one of the constant efforts of human thought. In this paper we sustain that Michel Foucault has offered a decisive contribuition to a better understanding of these social phenomena. In the first part, we examine some characteristics of Foucault's concept of power. In the second, we followed the transformations which this concept suffered along the seventies in his work.

\section{REFERÊNCIASBIBLIOGRÁFCAS}

Deleuze, Gilles. (1986) Foucault. Paris, Les Éditions de Minuit.

Escobar, Carlos Henrique de (org). (1984) Dossier. Rio de Janeiro, Ed. Taurus.

EwALD, François. (1975) Anatomie et corps politique. Critique, Paris, nº 343, Édition de Minuit.

Foucault, Michel. (1974-82) Anuário do Collège de France.

. (1977) Vigiar e punir. Petrópolis, Ed. Vozes.

. (1979a) Microfísica do poder. Rio de Janeiro, Ed. Graal.

. (1979b) A vontade de saber. $2^{a}$ edição. Rio de Janeiro, Ed. Graal.

. (1980a) L'impossible prison, recherches sur le systeme pénitentiaire au XIX siècle. Paris, Éd. du Seuil.

. (1980b) Power and knowledge. New York, Pantheon Books.

. (1982) Subject and Power. In: Dreyfuss, H. \& Rabinow P. Beyond structuralism and hermeneutics. Brighton, The Harvester Press.

Machado, Roberto. (1979) Por uma genealogia do poder. In: Foucault, Michel. Microfísica do poder. Rio de Janeiro, Ed. Graal.

. (1982) Ciência e saber - a trajetória da arqueologia de Foucault. Rio de Janeiro, Ed. Graal.

MARIETTI, Angèle K. (1977) Introdução ao pensamento de Michel Foucault. Rio de Janeiro, Zahar Editores.

UNITERMS:

Foucault, concept of power, bio-power, governmentability. 
MAIA, Antônio C. Sobre a analítica do poder de Foucault. Tempo Social; Rev. Sociol. USP, S. Paulo, 7(1-2): 83-103, outubro de 1995. 